\title{
A study of the factors affecting the receding age of onset of menarche in young girls
}

\section{Noor Dharmarha*, Anuradha Konda}

Department of Obstetrics and Gynecology, Dr. Babasaheb Ambedkar Memorial Central Railway Hospital, Byculla East, Mumbai, Maharashtra, India

Received: 09 May 2018

Accepted: 31 May 2018

\section{*Correspondence:}

Dr. Noor Dharmarha,

E-mail: drnoord11@gmail.com

Copyright: (c) the author(s), publisher and licensee Medip Academy. This is an open-access article distributed under the terms of the Creative Commons Attribution Non-Commercial License, which permits unrestricted non-commercial use, distribution, and reproduction in any medium, provided the original work is properly cited.

\section{ABSTRACT}

Background: Present study highlights that the worldwide trend of declining age at menarche is also seen in urban Indian girls. The aim of the study was to evaluate the age of menarche and to find out the factors associated with the timing of menarche.

Methods: The study was an observational cross sectional study. 258 healthy, menstruating, adolescent girls aged 1016 years, were selected by simple random sampling. Pre-designed structured questionnaires were distributed after taking informed consent. Anthropometric measurements were taken using standard techniques. The average age of menarche was calculated. The association of the age at menarche with the proposed factors was analyzed using chi square test and Pearson's correlation coefficient. "P value" less than 0.05 was considered as significant.

Results: The mean age at menarche was found to be $12.23 \pm 1.09$ years. The study found a strong association between the respondent's age at menarche and her sister's age at menarche $(p=0.002)$. The study also found a strong association between age at menarche and the socioeconomic status $(p=0.021)$. This study however found no association of menarcheal age with factors like birth weight, type of diet, frequency of milk intake, body mass index, waist hip ratio, amount of exercise, unstable environment at home and psychosocial stress.

Conclusions: The worldwide trend of declining age at menarche is also seen in urban Indian girls. This trend underlines the importance of investigating the factors associated with it and studying the future implications of a lower age at menarche.

Keywords: Adolescent gynaecology, Early menarche, Menarche, Puberty

\section{INTRODUCTION}

Early age at menarche is a universal trend nowadays, and determining the correlating factors and associated consequences is important.

Early menarche has biomedical, emotional, and sociocultural consequences, including predisposition to diseases such as cancer and heart disease and early participation in risky behaviours, such as cigarette smoking, drug abuse, and sexual activity. Early pubertal development is also linked with slightly decreased adult height and an increased risk for obesity, compared to later age of menarche.

The aims and objectives of this study were to evaluate the age of menarche in adolescent girls, to detect the factors affecting age at menarche and to find the association of these factors with the age at menarche.

The exact causes of a changing age at menarche are indefinite and multifactorial. Age at menarche depends 
on both genetics and environmental and social experiences. If the age of menarche was determined only by genetics, young girls everywhere would reach menarche around the same age. However, it is clearly not the case. Thus, environment and culture also have an influence on menarcheal age.

Although scholars do not know what exactly triggers puberty in humans, we do know the process starts in the brain in connection to the endocrine system.

Steingraber in 2007 suggested that the HPO axis is an internal monitor, which is very sensitive to disruptions, and can trigger the premature release of estrogen in girls. ${ }^{1}$ Therefore, the relationship between the brain and the external environment is a crucial element in the onset of puberty.

While Delemarre-van de Waal suggests that environmental factors could outweigh the influence genetics has on timing of menarche, a consideration of genetic predisposition to timing of menarche still needs to be considered. ${ }^{2}$

Belsky et al, in suggested that even societal factors affect timing of puberty because children are socialized to be sensitive to availability and reliability of resources, both biological and emotional. ${ }^{3}$

\section{METHODS}

It was an observational cross sectional study

Adolescent girls aged 10-16 years attending Gynecology OPD at Dr. Babasaheb Ambedkar Central Railway Hospital, Byculla, Mumbai, Maharashtra, India were recruited from August 2015 to March 2017.

\section{Data collection}

Using the observational method, questionnaires were distributed to girls after obtaining informed consent. The questionnaire included socio-demographic information about the respondent age, educational status of self and family income and residence. The questions related to menstruation comprised age of menarche, dietary habits, weight, height, level of physical activity, stress levels, age of menarche in sisters, exposure to cigarette smoke, divorce of parents.

The questionnaire was verbally interpreted in simple language and properly explained to avoid any form of misunderstanding and to facilitate accurate response by the subject. The respondents were instructed not to discuss answers amongst themselves and the questionnaires were collected immediately after completion to minimize interpersonal communication amongst the subjects and to prevent the influence of friends on individual response.

\section{Inclusion criteria}

10-16 year old girls with onset of menarche present.

\section{Exclusion criteria}

Girls with chronic medical/surgical/chromosomal disorders.

For this study, data was obtained by simple random sampling. Girls aged 10-16 years, having attained menarche and not fitting the exclusion criteria were recruited at random from the adolescent girls attending gynaecology OPD.

\section{Variables}

- Age of participants: age of the participant in completed years.

- Socioeconomic status: socioeconomic status according to Kuppuswamy Status Scale (2017) taking CPI as $274 .^{4}$

- Age at menarche: Age in years closest to the completed year.

- Sister's age at menarche: Age in years closest to the completed year.

- Birth weight: Birth weight in kilograms, as recalled by the participant to the nearest 100 grams.

- Frequency of milk intake: Number of servings of milk consumed by the participant in a week.

- Body mass index: Weight (in kilograms) divided by square of the height (in metres). Classified according to Asian cut-offs as underweight (less than 18.5 $\mathrm{kg} / \mathrm{m} 2)$, normal (18.5-23 kg/m2), overweight (23$27.5 \mathrm{~kg} / \mathrm{m} 2$ ) and obese ( more than $27.5 \mathrm{~kg} / \mathrm{m} 2$ ). ${ }^{5}$

- Waist-Hip ratio: Waist circumference (in inches) divided by hip circumference (in inches). Classified as excellent (less than 0.75), good (0.75-0.79), average $(0.80-0.86)$ and at risk for cardiovascular disease (more than 0.86). ${ }^{6}$

\section{Data sources/measurement}

Pre-designed structured questionnaires were distributed. After a brief explanation of the work and nature of questions raised in the questionnaire, respondents who agreed to participate in the study were advised to feel free to ask any of the research assistant's questions they found difficult to understand. Permission to conduct the study was obtained from the mother/guardian. To assess age at menarche, each participant was asked if she had had her first menstrual period. Anthropometric measurements of weight, height, hip and waist circumferences were measured height was measured with a stadiometer (190 cm long). ${ }^{7}$ Subjects stood bare-foot with arms straight and relaxed and the head held in the Frankfort plane. Weight was taken using a beam scale (capacity $120 \mathrm{~kg}$ ). Subjects wore only light clothing, and the scale was checked each day for accuracy and precision. Waist and 
hip circumference was measured with an inelastic tape (140 cm long) while subjects stood with shoulders and arms relaxed. The research assistant faced the subject while passing the tape around the waist and hip. Waist circumference was measured with the tape wrapped around the smallest part of the abdomen. Hip circumference was measured with the tape wrapped around the largest part of the buttock. All circumferences were measured with subject standing. BMI was calculated as weight $(\mathrm{kg})$ divided by the square of height (m) and classified according to Asian cut-offs as underweight $(<18.5)$, normal $(18.5-23)$, overweight $(23$ $27.5)$ and obese $(>27.5)$. Waist hip ratio was calculated by dividing the waist circumference by the hip circumference and classified as excellent $(<0.75)$, good (0.75-0.79), average (0.80-0.86) and at risk for cardiovascular events $(>0.86)$.

\section{Bias}

There was a recall bias in questions pertaining to exact age at menarche and birth weight. This was reduced by getting the questionnaires filled in the presence of the respondent's mother. However, certain sensitive questions related to sexual debut and drug abuse faced response bias as girls were uncomfortable answering these questions in their mothers' presence. To reduce this response bias, these questions were asked in private by the principal investigator while taking anthropometric measurements.

\section{Study size}

Sample size for this study was 258 .

Justification of sample size-

To calculate sample size, following formula is used:

\section{$\mathrm{N}=\mathrm{Z} 2 \times \mathrm{P}(1-\mathrm{P}) / \mathrm{d} 2$}

Where

$\mathrm{Z}=$ standard normal deviate $=1.96$ (at 95\% confidence interval)

$\mathrm{d}=$ margin of error (precision) will be 0.05

$\mathrm{P}=$ prevalence of girls attaining menarche around 12 years of age

According to recent studies, maximum numbers of girls are achieving menarche around the age of 12 years Mane K.S. et al. ${ }^{8}$ Hence we take rough estimate of prevalence of age at menarche as 12 years to be $80 \%$.

So, $\mathrm{p}=80 \%=0.8$

That makes $\mathrm{N}=245.86$

So calculated sample size is 246 .

However data available in OPD shows about 900 adolescent girls attended our hospital in a year. A finite population correction formula was used to adjust sample size, so that it provides proportionately more information for small population $\mathrm{N}$.
Final sample size

$$
n=\frac{\mathrm{N}}{1+[(N-1) / n e}
$$

Where,

$\mathrm{n}=$ final minimum sample size

$\mathrm{N}=$ sample size calculated using the above formula

ne $=$ number of adolescent girls attending paediatric OPD in a year.

That makes $\mathrm{n}=193.36$

So, final sample size is 194 .

Though the calculated sample size was 194, we took 258 girls from the railway population in Mumbai, Maharashtra, India for our study. As this is a population based study, increasing the study sample will only increase the strength of study and give results which might be extrapolated to the entire population.

\section{Statistical methods}

The data was entered in Microsoft Excel and the average age of menarche was calculated.

Data was analyzed using SPSS version 20.0. Qualitative data was represented in the form of tables, bar diagrams and pie chart and quantitative data was represented with mean and standard deviation. The association between two qualitative data was done by chi square test. The correlation between two variables was done with Pearson's correlation coefficient and $\mathrm{p}$ value less than 0.05 was considered as significant.

Only completely filled questionnaires were included in the study. Forms with missing data were excluded. After excluding the incompletely forms, 258 questionnaires were remaining, which were taken up for the analysis.

\section{RESULTS}

The study found the mean age at menarche to be $12.23 \pm 1.09$ years

Table 1: Distribution of study participants according to age at menarche.

\begin{tabular}{|lll|}
\hline $\begin{array}{l}\text { Age at menarche (in } \\
\text { years) }\end{array}$ & Number & Percentage \\
\hline $9.0-9.9$ & 4 & 1.6 \\
\hline $10.0-10.9$ & 15 & 5.8 \\
\hline $11.0-11.9$ & 35 & 13.6 \\
\hline $12.0-12.9$ & 128 & 49.6 \\
\hline $13.0-13.9$ & 30 & 11.6 \\
\hline 14 & 46 & 17.8 \\
\hline Total & 258 & 100.0 \\
\hline
\end{tabular}


The study found a strong association between the respondent's age at menarche and her sister's age at menarche $(\mathrm{p}=0.002)$.

Table 2: Distribution of study participants according to sister's age at menarche.

\begin{tabular}{|lll|}
$\begin{array}{l}\text { Sister's age at } \\
\text { menarche in years } \\
(\mathbf{n}=121)\end{array}$ & Number & Percentage \\
\hline $10-12$ & 34 & 28.1 \\
\hline $12-14$ & 61 & 50.4 \\
\hline $14-16$ & 26 & 21.5 \\
\hline Total & 121 & 100.0 \\
\hline
\end{tabular}

Table 3: Correlation between participants' age of onset of menses with her sister's age of onset of menses.

\begin{tabular}{|ll|}
\hline $\begin{array}{l}\text { Pearson's correlation } \\
\text { Participant's age at } \\
\text { menarche }\end{array}$ & 0.273 \\
\hline P value & 0.002 \\
\hline
\end{tabular}

The correlation between participant's age at menarche and her sister's age at menarche was found to be having a positive association and it was statistically significant.

The study also found a strong association between age at menarche and the socioeconomic status $(\mathrm{p}=0.021)$.

Table 4: Association between socioeconomic status and age at menarche.

\begin{tabular}{|llll|}
\hline Socioeconomic status & \multicolumn{2}{l}{ Age at Menarche } & Total \\
\hline High $($ Class I and II) & $\mathbf{1 2}$ years & $\mathbf{> 1 2}$ years & $224(100.0 \%)$ \\
\hline Low $($ Class III and IV) & $52(23.2 \%)$ & $172(76.8 \%)$ & $34(100.0 \%)$ \\
\hline Total & $02(5.9 \%)$ & $32(94.1 \%)$ & $258(100.0 \%)$ \\
\hline Chi square $=5.358$, df $=1$, p value $=0.021$ & $204(79.1 \%)$ & \\
\hline
\end{tabular}

In high socioeconomic classes, $23.2 \%$ of the participants had age at menarche $\leq 12$ years while in low socioeconomic classes it was only $5.9 \%$ and the difference was found to be statistically significant.

Birth weight $(\mathrm{p}$ value $=0.736)$ : In low birth weight $(<2.5$ $\mathrm{kg}$ ) group, $22.8 \%$ respondents had age at menarche $\leq 12$ years while in normal and high birth weight babies $(>3.5$ $\mathrm{kg}$ ), it was $20.1 \%$ and $15.4 \%$ respectively. The association between two variables were not statistically significant.

Type of $\operatorname{diet}($ vegetarian/non-vegetarian $)$ ( $\mathrm{p}$ value $=$ 0.783 ): $22.0 \%$ of the vegetarian had age at menarche $\leq 12$ years while $20.5 \%$ of participants who consumed mixed diet had attended the same and the difference was not statistically significant.

Frequency of milk intake $(\mathrm{p}$ value $=0.797)$ : Participants who all consumed milk, $21.4 \%$ had age at menarche $\leq 12$ years while those who didn't consume milk had $20.0 \%$ of the same. This difference was not statistically significant.

Body mass index $(\mathrm{p}$ value $=0.116)$ : Overweight and obese participants $(30.8 \%)$ had comparatively early menarche as compare to normal $(23.0 \%)$ and underweight $(16.0 \%)$ participants but the association is not statistically significant.

Waist hip ratio $(\mathrm{p}$ value $=0.731)$ : Participants with waist hip ratio $\leq 0.86(21.2 \%)$ had comparatively early menarche as compared to those who had $>0.86(17.6 \%)$ and the association is not statistically significant.

Amount of exercise $(\mathrm{p}$ value $=0.157)$ : Participants with low exercises, early menarche was attended by $18.1 \%$ of respondents while in moderate exercises it was $25.5 \%$. The association between exercise and age at menarche was not statistically significant.

Unstable environment at home $(\mathrm{p}$ value $=0.354)$ : Participants with unstable environment had comparatively late menarche $(83.3 \%)$ as compared to those had stable environment $(77.8 \%)$ and the difference is not statistically significant.

Psychosocial stress $(\mathrm{p}$ value $=0.243$ ): $23.2 \%$ of the participants with stress had attended early menarche as compare to $17.0 \%$ in without stress group and this difference is not statistically significant.

\section{DISCUSSION}

The receding age of menarche is a universal trend nowadays, as reported by several studies and is associated with serious future implications. ${ }^{9-18}$ Thus determining the age of menarche in our urban Indian population and the associated factors is of paramount importance.

Various factors have been studied in several studies, yet the exact causal relationship is yet to be established. 
Our study aims to fill the lacunae in literature and to add to our existing knowledge about the age at menarche and the degree of association with the implicated factors in the present day scenario.

We did an observational cross section study on 258 girls aged 10-16 years, selected from the OPD population by simple random sampling. These girls filled a predesigned questionnaire and standard anthropometric measurements were taken for each participant. Data were analyzed using SPSS V20.0 (Statistical Package for Social Sciences, Version 20.0)

All the girls in the present study were city dwellers, staying at Mumbai, Maharashtra, India.

We found the mean age at menarche to be $12.23 \pm 1.09$ years and most $(49.6 \%)$ respondents reported that they attained menarche between 12-12.9 years of age. This declining trend of age at menarche has also been seen in several other Indian studies, for example, a similar study done by Mane KS et al, found the mean age at menarche to be 12.14 years. Studies by P. Iyer et al and by S. Sinha et al, found the mean age at menarche to be 12.7 and 12.69 years respectively. 9,10

This trend of declining puberty has also been reported by several studies done in other countries, for instance, by Noipayak P et al, in 2017 in Dusit district, Bangkok and by Mpora BO, Piloya in northern Uganda. ${ }^{11,12}$ Steingraber S, reported a similar trend in Europe, Anderson SE, Must. $A$ in USA, and Ulijaszek SJ, Evans E among IndoPakistani girls. ${ }^{1,13,14}$ This declining age at menarche has been linked to a disparity between biological maturation and psychosocial maturation, as found by a study done in 2006 by Gluckman P, Hanson M. ${ }^{19}$

Our study found a strong association between the respondent's age at menarche and her sister's age at menarche $(\mathrm{p}=0.002)$ as $50.4 \%$ respondents reported their sister's age of menarche to be between $12-14$ years. The mean age at menarche for the respondents' sisters was observed to be $12.26 \pm 1.144$ years

Our study is supported by the studies done by Graber JA et al and Meyer et al which support genetics as a cause for earlier menarche. ${ }^{20,21}$ However, studies done by Towne et al, and Susman and Dorn have suggested that genetics accounts for about half of the variance in timing of menarche, but no single gene has been found that controls timing of puberty and that intrinsic factors are not the only determinates of age at menarche for a girl. ${ }^{22,23}$

$61.2 \%$ girls taken in our study belonged to upper middle socioeconomic status according to the latest Kuppuswamy scale (2017). Our study found a strong correlation between age at menarche and the socioeconomic status $(\mathrm{p}=0.021)$, that is, higher socioeconomic class was strongly associated with earlier age at menarche. Similar findings were reported by Mane $\mathrm{KS}$ et al, Yarmechenko et al. ${ }^{18,24}$ Our finding was also supported by the study done by Dvornyk et al in developing countries. ${ }^{25}$

Our study found no significant association between birth weight and age at menarche $(\mathrm{p}=0.736)$. Upon reviewing the literature, we found conflicting data about the role of birth weight on the age of menarche. Our finding was supported by studies done by Raveendran RC et al, which also found no statistically significant correlation between birth weight and age at menarche. ${ }^{26}$ However, our study was in contrast with studies done by by Steingraber which found that birth weight is a significant predictor of age at menarche. ${ }^{1}$

Type of diet, especially intake of animal fat and protein has been proposed as a possible factor in determining age at menarche. However, our study found no significant correlation between age of menarche and the type of diet $(\mathrm{p}=0.783)$, and similar ages at menarche were reported for vegetarians and non-vegetarians. This indicates that some other factors, apart from diet are responsible for predicting the age at menarche. Our finding is supported by the study done by Castilho SD et al. ${ }^{27}$ However, our findings were contrasting with those of the studies done by Gunther ALB et al, which have linked animal fat and protein intake to lower age at menarche. ${ }^{28}$

We found no significant association with frequency of milk intake and early age at menarche $(p=0.797)$. Our study is supported by the study done by Carwile JL et al, which also found no significant association of milk intake with age at menarche. ${ }^{29}$ On the other hand, studies done by Hoppe $\mathrm{C}$ et al, in 2004 have associated milk intake to pubertal development, and the study done by Chevalley $\mathrm{T}$. et al, has linked high calcium intake to early age at menarche. ${ }^{30,31}$

With increasing prevalence of childhood obesity and metabolic syndrome, special emphasis is being put on body mass index and waist hip ratio among adolescents. Physical exercise, which a direct predictor of obesity and $\mathrm{BMI}$, is also on the decline among adolescents, with an ever increasing number of girls leading a sedentary life, spending their free time watching TV or playing games on cell phones.

Our study found no significant correlation between BMI and age at menarche $(\mathrm{p}=0.116)$. Our findings are consistent with those of Raveendran RC et al, that there is no significant correlation was found between BMI and age of menarche. ${ }^{26}$ Our study is also supported by Rao S et al, who challenged the critical weight hypothesis. ${ }^{32}$ However our result is contrasting with several studies by Guo and Ji and Qing et al, which reported decrease in age at menarche with every unit increase in BMI..$^{33,34}$

We found no significant association between waist hip ratio and age at menarche $(\mathrm{p}=0.731)$. Our study correlates 
with the study done by W.D. Lassek et al, who concluded that unit increase in waist circumference lowers the odds at menarche by $7 \% .{ }^{35}$ They also found that increase in gluteofemoral fat distribution increases the odds at menarche by $22 \%$. Our result is however in contrast with the study done by Guo and Ji, who have given a strong association between age at menarche and increased waist circumference. ${ }^{33}$ Also, present study found no significant association between age at menarche and amount of exercise $(p=0.157)$. This was in contrast to studies reported by Steingraber and Grumbach and Styne. ${ }^{1,36}$

Stress is an important psychological factor affecting teenagers nowadays. The causes of stress are varied, and may be due to negative body image, peer pressure, increased competition and academic pressure, stress due to unstable environment at home, alcoholic father and broken families, among many other possible stressors. Our study did not show any significant association of age at menarche with unstable environment $(\mathrm{p}=0.354)$ or with psychological stress $(\mathrm{p}=0.243)$. Our result is supported by studies done by Meulenijzer E et al and Mpora and Piloya. ${ }^{11,37}$ However several studies have reported that in father's absence, in the presence of psychological stress and in disrupted families, girls attain menarche earlier.,3840

\section{CONCLUSION}

Our study has thus shown that the age at menarche is showing a declining trend. This trend underlines the importance of investigating the factors associated with it and studying the future implications of a lower age at menarche. This study revealed the mean age at menarche to be $12.23 \pm 1.09$ years, which parallels the trend seen in several studies. The outcome of our study is that socioeconomic status and genetic factors have a bearing on the mean menarcheal age.

A majority of girls in our study who attained menarche at an early age had normal BMI. This point to the fact that there could probably be a role of other external factors like endocrine-disruptive chemicals with oestrogen like properties responsible for the receding age of menarche in urban India, which needs to be further, studied.

To conclude, earlier occurrence of menarche is an ominous event with long term risks which can be prevented by identifying the associated risk factors, adopting a healthy life style and self-care.

\section{Funding: No funding sources}

Conflict of interest: None declared

Ethical approval: Not required

\section{REFERENCES}

1. Steingraber S. The falling age of puberty in US girls: what we know, what we need to know. 2007. Breast Cancer Fund: San Francisco;2011:72.
2. Delemarre-van de Waal HA. Secular trend of timing of puberty. In Abnormalities in Puberty. 2005;8:114.

3. Belsky J, Steinberg L, Draper P. Childhood experience, interpersonal development, and reproductive strategy: An evolutionary theory of socialization. Child Dev. 1991;62(4):647-70.

4. Sharma R. Kuppuswamy's Socioeconomic Status Scale-revision for 2011 and formula for real-time updating. Indian J Pediatr. 2012;79(7):961-2.

5. Barba C, Cavalli-Sforza T, Cutter J, Darnton-Hill I. Appropriate body-mass index for Asian populations and its implications for policy and intervention strategies. Lancet. 2004;363(9403):157.

6. World Health Organization. Waist circumference and waist-hip ratio: Report of a WHO expert consultation, Geneva; 2008.

7. Frisancho AR. Anthropometric standards for the assessment of growth and nutritional status. University of Michigan Press; 1990.

8. Mane KS, Sharankumar H, Bheemayya B. Age At Menarche and Factors Associated among Girls of a Primary Health Centre Area in Davangere, India. Community Med. 2016;7(5):417-20.

9. Iyer P, Modi JN. Menstrual cycle characteristics and associated physical problems among school going adolescent girls. Int J Reprod, Contracep, Obstet Gynecol. 2017;4(4):1076-8.

10. Sinha S, Srivastava JP, Sachan B, Singh RB. A study of menstrual pattern and prevalence of dysmenorrhea during menstruation among school going adolescent girls in Lucknow district, Uttar Pradesh, India. Int $\mathbf{J}$ Comm Med Public Health. 2017;3(5):1200-3.

11. Noipayak P, Rawdaree P, Supawattanabodee B, Manusirivitthaya S. Factors associated with early age at menarche among Thai adolescents in Bangkok: A cross-sectional study. BMC women's health. 2017;17(1):16.

12. Mpora BO, Piloya T, Awor S, Ngwiri T, Laigong P, Mworozi EA, Hochberg ZE. Age at menarche in relation to nutritional status and critical life events among rural and urban secondary school girls in post-conflict Northern Uganda. BMC women's health. 2014;14(1):66.

13. Anderson SE, Must A. Interpreting the continued decline in the average age at menarche: results from two nationally representative surveys of US girls studied 10 years apart. J Pediatr. 2005;147(6):75360.

14. Ulijaszek SJ, Evans E, Miller DS. Age at menarche of European, Afro-Caribbean and Indo-Pakistani schoolgirls living in London. Annals Human Biol. 1991;18(2):167-75.

15. Lakshman R, Forouhi NG, Sharp SJ, Luben R, Bingham SA, Khaw KT, Wareham NJ, Ong KK. Early age at menarche associated with cardiovascular disease and mortality. J Clin Endocrinol Metab. 2009;94(12):4953-60.

16. Chevalley T, Bonjour JP, Ferrari S, Rizzoli R. The influence of pubertal timing on bone mass 
acquisition: a predetermined trajectory detectable five years before menarche. J Clin Endocrinol Metab. 2009;94(9):3424-31.

17. Gerdhem P, Obrant KJ. Bone mineral density in old age: the influence of age at menarche and menopause. J Bone Mineral Metabolism. 2004;22(4):372-5.

18. Dunger DB, Ahmed ML, Ong KK. Effects of obesity on growth and puberty. Best Pract Res Clin Endocrinol Metab. 2005;19(3):375-90.

19. Gluckman PD, Hanson MA. Evolution, development and timing of puberty. Trends Endocrinol Metab. 2006;17(1):7-12.

20. Graber JA, Brooks-Gunn J, Warren MP. The antecedents of menarcheal age: Heredity, family environment, and stressful life events. Child Development. 1995:346-59.

21. Meyer JM, Eaves LJ, Heath AC, Martin NG. Estimating genetic influences on the age-at-menarche: a survival analysis approach. Am J Med Genetics. 1991;39(2):148-54.

22. Towne B, Czerwinski SA, Demerath EW, Blangero J, Roche AF, Siervogel RM. Heritability of age at menarche in girls from the Fels Longitudinal Study. Am J Physical Anthropol. 2005;128(1):210-9.

23. Susman EJ, Dorn LD. Its role in development. handbook of adolescent psychology. Individual Bases Adoles Dev. 2009;1:116.

24. Yermachenko A, Dvornyk V. Nongenetic determinants of age at menarche: a systematic review. BioMed Res Int. 2014:23;2014.

25. Dvornyk V. Genetics of age at menarche: a systematic review. Human Reprod Update. 2012:dmr050.

26. Raveendran RC, Jacob AM, Ismail J. Does birth weight influence the age of menarche? A cross sectional study in rural Kerala. JEMDS. 2017;6(1):10-3

27. Castilho SD, Nucci LB. Age at menarche in schoolgirls with and without excess weight. Jornal de Pediatria (Versão em Português). 2015;91(1):75-80.

28. Günther AL, Karaolis-Danckert N, Kroke A, Remer $\mathrm{T}$, Buyken AE. Dietary protein intake throughout childhood is associated with the timing of puberty. $\mathrm{J}$ Nutri. 2010;140(3):565-71.

29. Carwile JL, Willett WC, Wang M, Rich-Edwards J, Frazier AL, Michels KB. Milk consumption after age 9 years does not predict age at menarche. J Nutri. 2015;145(8):1900-8.
30. Hoppe C, Mølgaard C, Juul A, Michaelsen KF. High intakes of skimmed milk, but not meat, increase serum IGF-I and IGFBP-3 in eight-year-old boys. Eur J Clin Nutri. 2004;58(9):1211-6.

31. Chevalley T, Rizzoli R, Hans D, Ferrari S, Bonjour JP. Interaction between calcium intake and menarcheal age on bone mass gain: an eight-year follow-up study from prepuberty to postmenarche. J Clini Endocrinol Metab. 2005;90(1):44-51.

32. Rao S, Joshi S, Kanade A. Height velocity, body fat and menarcheal age of Indian girls. Indian Pediatr 1998;35:619-28.

33. XiaoYan GU, ChengYe JI. Earlier menarche can be an indicator of more body fat: study of sexual development and waist circumference in Chinese girls. Biomed Environment Sci. 2011;24(5):451-8.

34. He Q, Karlberg J. BMI in childhood and its association with height gain, timing of puberty, and final height. Pediatric Res. 2001;49(2):244-51.

35. Lassek WD, Gaulin SJ. Brief communication: menarche is related to fat distribution. Am J Phys Anthropol. 2007;133(4):1147-51.

36. Grumbach MM, Styne DM. Puberty: ontogeny, neuroendocrinology, physiology, and disorders. Williams Textbook Endocrinol. 1998;9:1509-625.

37. Meulenijzer E, Vyncke K, Labayen I, Meirhaeghe A, Béghin L, Breidenassel C, et al. Associations of early life and sociodemographic factors with menarcheal age in European adolescents. Eur $\mathbf{J}$ Pediatr. 2015;174(2):271-8.

38. Ellis BJ, Garber J. Psychosocial antecedents of variation in girls' pubertal timing: maternal depression, stepfather presence, and marital and family stress. Child Dev. 2000;71(2):485-501.

39. Jorm AF, Christensen H, Rodgers B, Jacomb PA, Easteal S. Association of adverse childhood experiences, age of menarche, and adult reproductive behavior: does the androgen receptor gene play a role?. Am J Med Genetics Part B: Neuropsychiatric Genetics. 2004;125(1):105-11.

40. Boynton-Jarrett R, Harville EW. A prospective study of childhood social hardships and age at menarche. Annal Epidemol. 2012;22(10):731-7.

Cite this article as: Dharmarha N, Konda A. A study of the factors affecting the receding age of onset of menarche in young girls. Int $\mathrm{J}$ Reprod Contracept Obstet Gynecol 2018;7:2813-9. 